\title{
Improving the properties of AA7075 resistance spot-welded joints by chemical oxide removal and post weld heat treating
}

\author{
Marcell Gáspár ${ }^{1}$ (1) - Ádám Dobosy ${ }^{1} \cdot$ Miklós Tisza $^{1} \cdot$ Imre Török $^{1} \cdot$ Yangchun Dong $^{2} \cdot$ Kailun Zheng $^{3}$
}

Received: 14 January 2020 / Accepted: 5 September 2020 / Published online: 18 September 2020

(C) The Author(s) 2020

\begin{abstract}
The aluminium alloy studied in this paper is the heat treatable AA7075 which has zinc as the main alloying element. 7xxx aluminium alloys have the best strength performance among all commercial series and AA7075 has tensile strength above $500 \mathrm{MPa}$. The outstanding strength properties open the possibility to use this alloy in automotive industry as a possible alternative material for car body elements instead of steel. However, their limited formability properties mean obstacle when a complicated shape car body panel is formed, since the elongation is limited only between 5 and $11 \%$. In order to successfully form these sheets into the demanded geometry, hot forming should be used, and thus the body panels should be formed when the AA7075 is in a solution heat treated condition, such as using the HFQ® process. Then, after assembling the body elements, when resistance spot welding is among the most common joining methods, the AA7075 body parts should get the artificial ageing. It means that welding is followed by artificial ageing as a kind of post weld heat treating which can partially compensate the softening of this alloy during welding. Softening is considered among the most challenging weldability issues similarly to the high melting point oxide layer at the surface which also reduces the load bearing capacity of RSW joints. During the performed experimental program, three routes were investigated. The RSW experiments are performed on 1-mm-thick AA7075 sheets. The spot-welded joints were examined by macroscopic testing, tensile shear and hardness tests.
\end{abstract}

Keywords Aluminium alloy $\cdot$ AA7075 $\cdot$ Resistance spot welding $\cdot$ HFQ $\cdot$ Oxide removal

\section{Introduction}

Due to their relatively low density and good resistance to corrosion, aluminium alloys are among the best engineering materials used in automotive industry [1-3]. The most commonly applied types are the 5xxx, 6xxx and 7xxx groups, for example: 5754, 6082 and 7075 respectively [4]. 7xxx

Recommended for publication by Commission III - Resistance Welding, Solid State Welding and Allied Joining Process

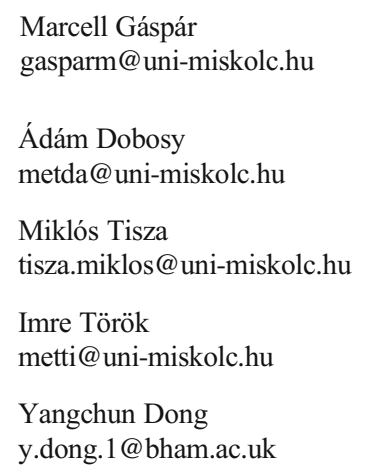

aluminium alloys have the best strength performance among all commercial series and AA7075 has tensile strength above $500 \mathrm{MPa}$. The outstanding strength properties open the possibility to use this alloy in automotive industry as an alternative material for car body elements instead of steels. The AA7075 aluminium alloys are used in various car body elements because of its high specific strength, low quench sensitivity,

Kailun Zheng

k.zheng13@imperial.ac.uk

1 Institute of Materials Science and Technology, University of Miskolc, Miskolc-Egyetemváros H-3515, Hungary

2 School of Metallurgy and Materials, University of Birmingham, Birmingham B15 2TT, UK

Department of Mechanical Engineering, Imperial College, London SW7 2AZ, UK 
wide range of solution heat treatment temperatures and rapid natural ageing characteristics. The AA7075 aluminium alloys can be effectively used in lightweight structures. In automotive industry, we can meet this alloy in body panels, brake housings, brake pistons, air deflector parts and seat slides (see Fig. 1).

High strength 7075 aluminium alloys are strengthened by precipitation hardening. This process involves raising the temperature of the alloy into the single-phase region where all the precipitates dissolve. The alloy is then rapidly quenched to form a supersaturated solid solution. The precipitates can be formed either slowly at room temperature (natural ageing) or more quickly at elevated temperatures (artificial ageing). The T6 temper state can be obtained either by ageing at $120^{\circ} \mathrm{C}$ for $24 \mathrm{~h}$ or $140{ }^{\circ} \mathrm{C}$ for $10 \mathrm{~h}$.

Besides the favourable properties of high strength aluminium sheets, there are still limitations for their wider application in the lower car categories. Replacing steel with lighter materials such as aluminium, magnesium etc. can be costly and is not simply straightforward [5]. Within the obstacles, not only the expensive base material but challenges of the production technology (e.g. metal forming, joining method) should be also considered [5,6]. Aluminium sheet has much lower formability at room temperature than typical sheet steels; therefore, new solutions should be developed [5]. Regarding the joining methods of aluminium alloys, the engineers face also difficulties which can be originated from the special properties (thermophysical characteristics, oxide layer, softening during heat input etc.) of aluminium.

Since one of the major obstacles to use high strength aluminium sheets is their limited formability; therefore, advanced forming technologies are also being investigated to form complex shaped parts from these alloys [5]. Advanced hot forming process including solution heat treatment (SHT), forming and

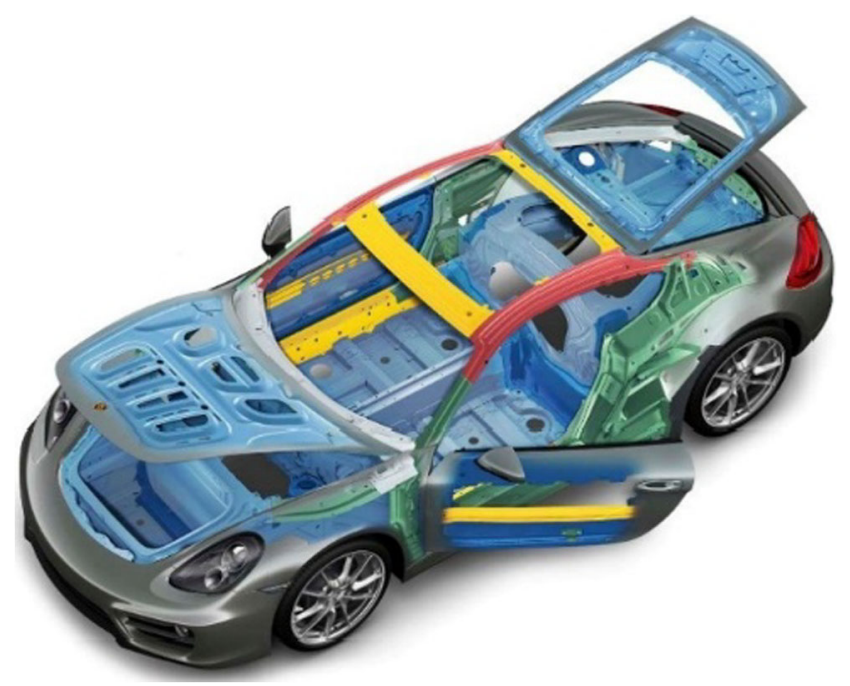

Fig. 1 Car body where the blue colours represent the high strength aluminium alloys [3] in-die quenching (hot form quench-HFQ) is one such technology [7]. In this process, the blank is first heated up to the SHT temperature. At this elevated temperature, the solid solubility is increased and the alloying elements, or precipitates, fully dissolve into the aluminium matrix. Consequently, the yield stress is reduced and the material becomes more ductile due to fewer obstacles to dislocation movement, enabling more complex shapes to be formed. The blank is transferred to a cold die, formed at a high speed and held in the cold tool to achieve a rapid cooling rate to room temperature. The fast pace of the process allows a supersaturated solid solution to be obtained [8].

After the successful pressing process, the car body elements should be joined to each other, usually with RSW. Finally, the assembled car body is generally moved to the paint shop, where the formed and joined aluminium sheets get a heat input according to the heat cycle during the paint bake. This heat input can be partially used for ageing in order to reach the demanded mechanical properties of the AA7075 alloy [9]. It means that the aluminium sheets are joined in a solution annealed (softened) and furthermore formed condition. Although it might be considered that the sheets are basically joined at the less deformed parts of the car body elements. Since the artificial ageing is partially connected to the painting of the car-body; therefore, the joint connections (RSW, FSW, clinching, adhesive bonding etc.) should be prepared before. It means that joints are heat treated as well, which might influence the mechanical properties of the weld metal and the heat-affected zone [10]. However, the paint bake cycle is not sufficient for the overall ageing due to the relatively short time $\left(180{ }^{\circ} \mathrm{C} \times 30 \mathrm{~min}\right)$; therefore, another ageing cycle can be implemented into the production chain. The whole process can be seen in Fig. 2.

\section{Resistance spot welding of aluminium alloys}

In automobile manufacturing, welding is one of the most important factors affecting the lifespan, safety, endurance, and quality of a vehicle. The most common welding method in the automotive industry is the resistance spot welding (RSW). RSW uses heat, obtained from resistance of the base materials and the connecting surfaces to electric current and mechanical pressure to create a weld between two pieces of metal. The weld is made by the combination of heat, pressure and time. One of the major advantages of RSW is the easy automation (high speed and adaptability) in high-volume production.

During spot welding, important changes occur in the mechanical and metallurgical properties of the spot-welded areas. The investigation of these changes is very important for the safety and quality of the welded joints which might have an effect on the whole structure. The welding current and time, 
Fig. 2 The whole cycle of the HFQ® process according to [11]

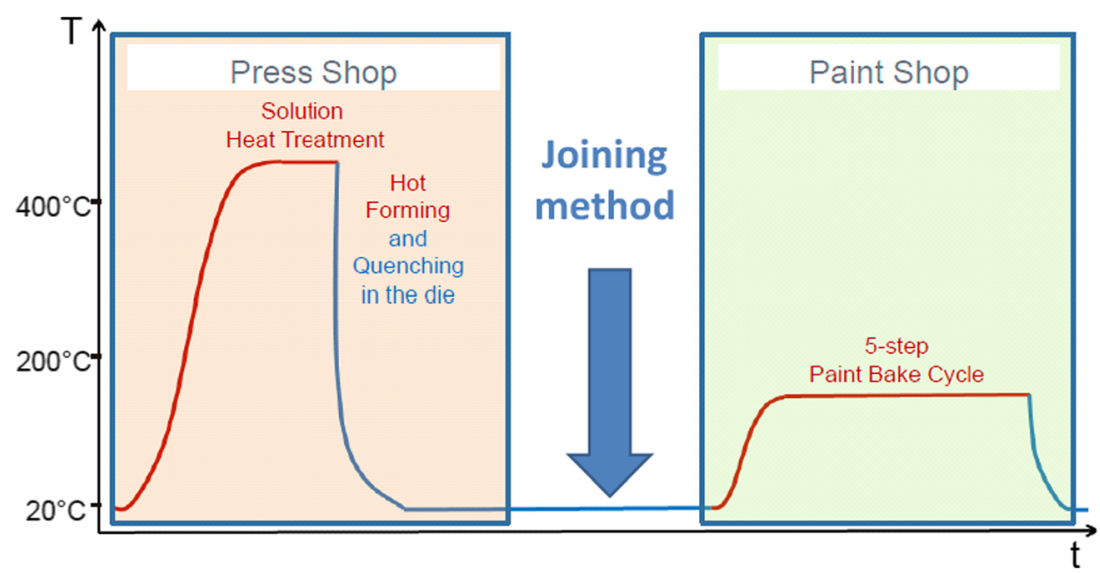

the applied pressure force and the total cycle diagram significantly influence the properties of spot welds.

Nowadays, there are acceptable solutions for the RSW of aluminium alloys; however, due to the characteristics of the base material (high melting point of the oxide layer at the surface, high thermal conductivity, low electrical resistance), we must take into consideration the following [12, 13]:

- In order to compensate the low electrical resistance and the better thermal conductivity of aluminium alloys, hard or extra hard program should be applied during resistance spot welding, which means high welding current and short welding time [14]. The necessary welding current can be 3-5 times higher compared with a similar thick steel sheet which requires high performance welding equipment. From the literature, it can be clearly seen that even for 1-mm-thick aluminium sheets, a high welding current (25-30 kA) and a relative short welding time ( $2-5$ cycles) should be applied in order to reach high load bearing capacity of the RSW joints.

- The presence of oxide layer generally affects the properties of the RSW joints; therefore, surface pre-treatment methods (Fig. 3) are suggested to be applied (e.g. chemical cleaning, etching, mechanical grinding, preheat cycle during welding). The necessity for surface pre-treatment methods is further justified since the aluminium welds are susceptible to porosity which can be originated from the surface contamination (grease, oil etc.). However, in industrial practice, the removal of the oxide layer is often neglected due to the technical difficulties and financial reasons $[15,16]$.

- The formation of shrinkage cavity and the avoidance of hot cracking can be treated by the application of higher post pressing force, which demand supplementary equipment in the welding machine. With higher forging load, the shrinkage cavity and the hot cracking can be avoided.
- The shape of the electrode end should be globular, thus the connected surfaces at the beginning are less and the current density is higher [17].

- The high strength of heat treatable aluminium alloys is guaranteed when the alloy is in an artificially aged (precipitation hardened) condition, which circumstances do not met in the weld and the heat-affected zone (HAZ). Therefore, a significant softening is expected compared with the base material as Fig. 4 shows.

The present research aims to investigate the effect of different heat conditions and hence the HFQ® process on the properties of RSW joints and to determine a welding technology including an efficient surface pre-treatment method for the oxide removal.

\section{Experimental method and material}

\subsection{Investigated material}

From the heat treatable aluminium alloys, the AA7075 alloy with $1 \mathrm{~mm}$ sheet thickness was chosen for our investigations. This base material includes mainly zinc, magnesium and copper, and its strength can be increased with annealing hardening, which is derived mainly from finely dispersed $\mathrm{MgZn} 2$ and $\mathrm{Mg} 3 \mathrm{Zn} 3 \mathrm{Al} 2$ precipitates both within grains and along grain boundaries [12]. The base material was delivered in $\mathrm{F}$ temper (as fabricated - no property limits specified) condition, which is acceptable for HFQ. Since this experimental AA7075 alloy is under development by the material producer, it has not been available in the market yet; therefore, just the typical chemical composition and mechanical properties are presented in Tables 1 and 2. If this aluminium base material is homogenized at $450{ }^{\circ} \mathrm{C}$ for several hours, quenched and then tempered at $120^{\circ} \mathrm{C}$ for $24 \mathrm{~h}$, the $\mathrm{T} 6$ condition can be achieved. 
Fig. 3 Surface pre-treatment methods for aluminium alloys [15]

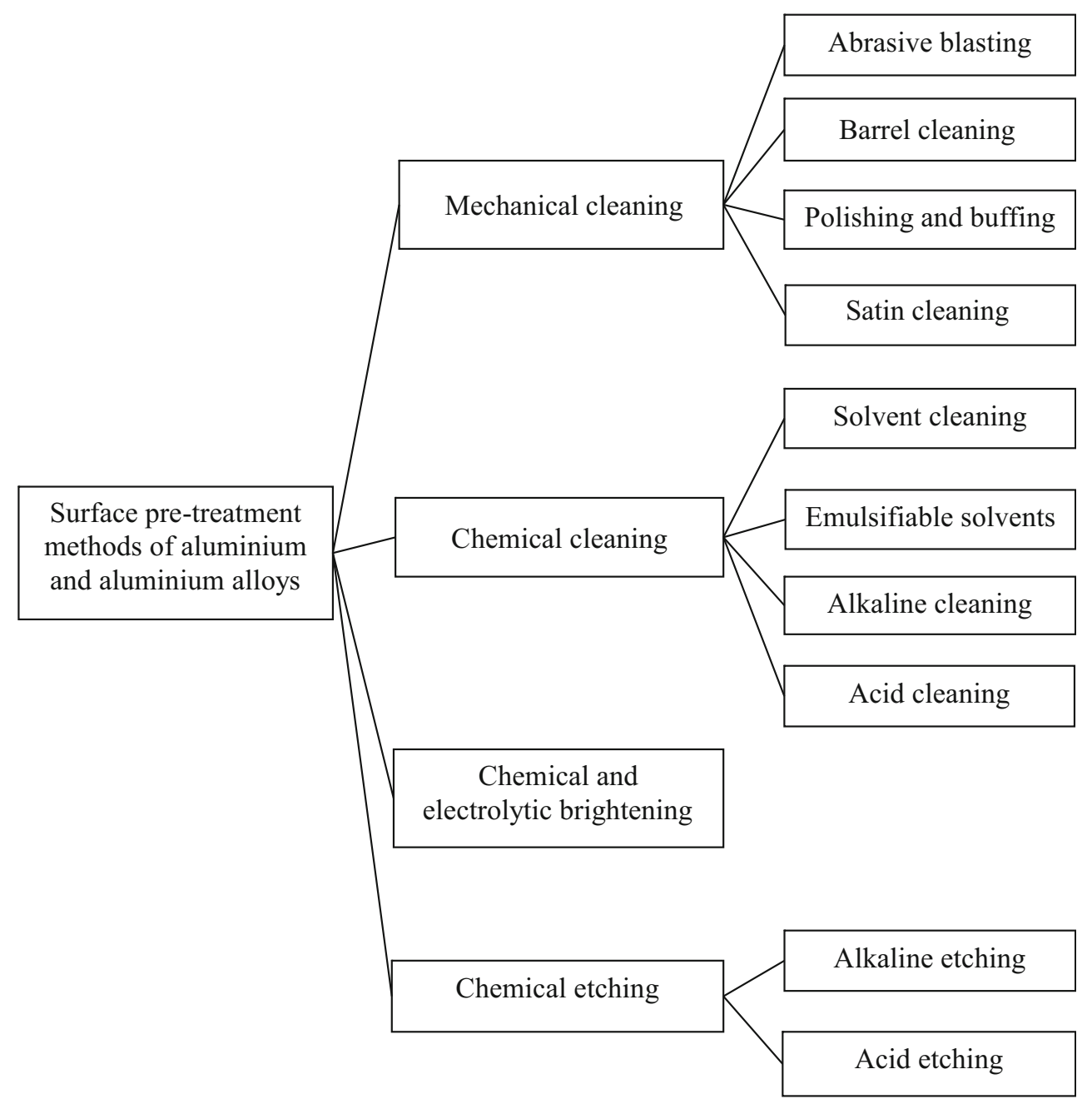

savings. The bracket sizes are valid in $0.5-1.5 \mathrm{~mm}$ range, according to standard EN ISO 14273. Welding was performed by overlapping the plates linearly in order to fabricate the specimens for later tensile shear tests.
The aluminium sheets were cut into $100 \times 30 \mathrm{~mm}$ specimens for the welding process (Fig. 5). Its dimensions differ from standard sizes with respect to material
Fig. 4 Softening of aluminium alloys during welding [13]

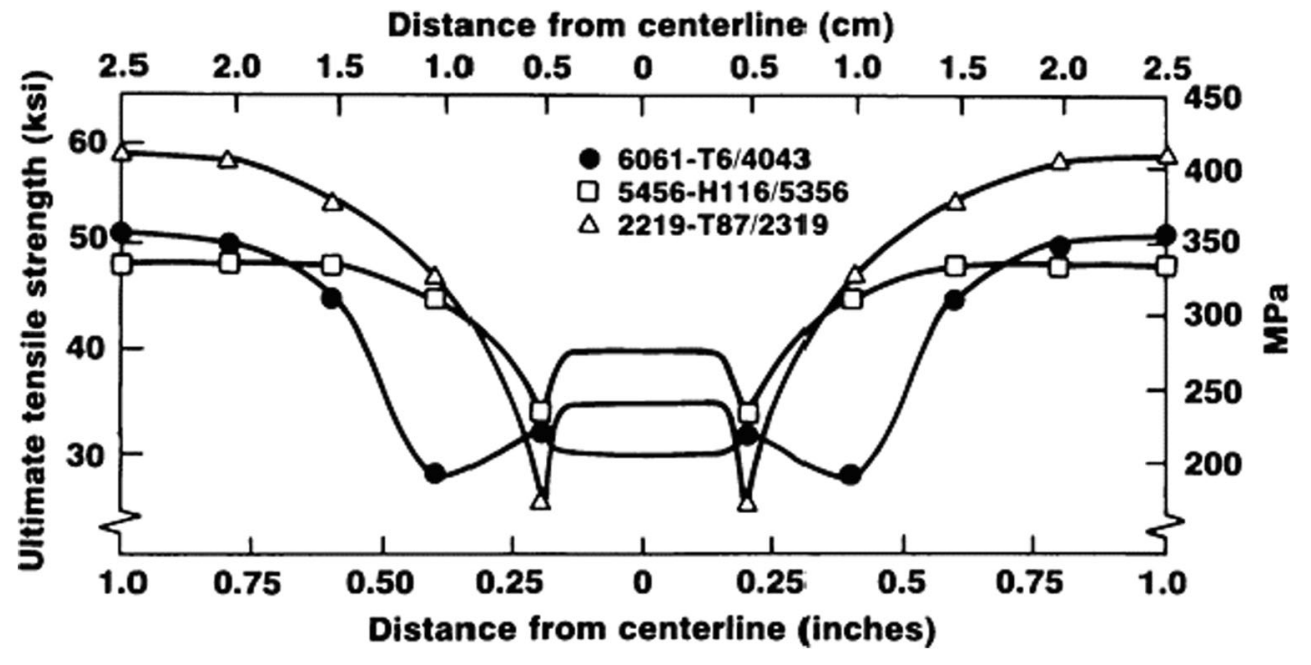


Table 1 Typical chemical composition of AA7075 aluminium alloy (wt\%)

\begin{tabular}{lllllllll}
\hline $\mathrm{Cu}$ & $\mathrm{Fe}$ & $\mathrm{Mn}$ & $\mathrm{Cr}$ & $\mathrm{Mg}$ & $\mathrm{Ti}$ & $\mathrm{Si}$ & $\mathrm{Zn}$ & $\mathrm{Al}$ \\
\hline $1.2-2.0$ & $\leq 0.5$ & $\leq 0.3$ & $0.18-0.28$ & $2.1-2.9$ & $\leq 0.2$ & 0.4 & $5.1-6.1$ & $87.1-91.4$ \\
\hline
\end{tabular}

Specimens were welded using a TECNA 8007 welding equipment with a TE 550 control unit, with a capability of a $26 \mathrm{kA}$ nominal weld current. The welding machine is equipped with a second valve and a pressure controller in order to realize a post pressing force for the avoidance of shrinkage cavity and hot cracking. A Cu-Al2O 3 composite electrode with a half sphere $7.5 \mathrm{~mm}$ radius was used for the experiments. The applied electrode is presented on Fig. 6.

After the preliminary successfully determined welding process window, a 7-cycle weld time with the achievable highest welding current $(26 \mathrm{kA})$ was set with two levels of electrode forces $(3-4 \mathrm{~s} \times 2.7 \mathrm{kN}$ and $2-3 \mathrm{~s} \times 4.4 \mathrm{kN})$, and with constant electrode hold time (7 cycles). The squeeze time $(t)$ and the forge time $(t)$ were set to 1 cycle; the total welding time $\left(t_{\mathrm{w}}\right)$ was 5 cycles and the upslope and downslope time was 1 cycle. In case of the current upslope and the downslope and in the force changing, the times are very short $(<0.5$ cycle). The whole welding cycle can be seen in Fig. 7.

The welding experiments were performed at room temperature and one cycle corresponds to $0.02 \mathrm{~s}$. Water was applied as a coolant at a rate of $5 \mathrm{l} / \mathrm{min}$. It is important to note that for even 1-mm-thick aluminium sheets, a higher performance equipment with higher welding current (24-30 kA) and therefore shorter welding cycle should be applied in order to maximize the hardness distribution and the tensile shear force by the welding parameters. In our case, we could not go above $26 \mathrm{kA}$; however, this welding current was appropriate for prepare acceptable RSW joints and to analyse the benefits of heat treating conditions and surface pre-treatment to the joint properties.

\subsection{Experimental program}

In order to analyse the effect of the oxide removal before joining, a surface pre-treatment method was designed which belongs to chemical etching methods [15]. This two-step method consists of a pre-pickle $\mathrm{NaOH}$ etching at elevated temperature followed by the mixture of $\mathrm{HNO} 3$ and HF pickle (Table 3).

Table 2 Typical mechanical properties of AA7075 aluminium alloy in T6 condition

\begin{tabular}{llll}
\hline$R_{\mathrm{m}}, \mathrm{MPa}$ & $R_{\mathrm{p} 0.2}, \mathrm{MPa}$ & $A_{50}, \%$ & $\mathrm{HV}$ \\
\hline $1.2-2.0$ & $\leq 0.5$ & $\leq 0.3$ & $0.18-0.28$ \\
\hline
\end{tabular}

Three processing routes were investigated in the function the base material heat treating condition and according to the location of joining process in the production chain (Table 4). In case of R1, the base material was in solution heat treated (softened) condition before joining and post weld ageing was not applied. In the second case (R2), the AA7075 was in T6 condition before joining without post weld heat treating. The third case is when the aluminium sheets are welded in a solution heat treated condition and after assembling the whole car body they get the ageing heat cycle.

\section{Results of discussion}

\subsection{Surface conditions after cleaning}

The elemental composition of aluminium surface was tested by glow-discharge optical emission spectroscopy (GDOES). The GDOES uses plasma to sputter aluminium surface from the top to the substrate, by which the OES gives quantitative element-depth profile and accurate percentage for oxygen. The changing of composition of AA7075 before and after pre-treatment is shown in Fig. 8. It can be seen that before the pre-treatment, there is a high level of $\mathrm{Mg}$ and $\mathrm{O}$ on the top surface, presumably from the SHT process. After pre-treatment with the alkaline immersion followed by HF acidic pickling, the surface is mostly free of oxidation that was formed during the previous SHT process.

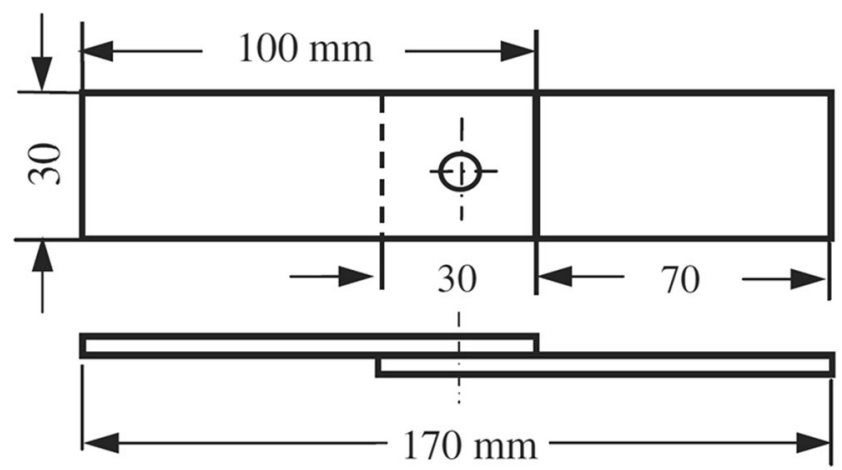

Fig. 5 Specimen configuration for the RSW experiments 
Fig. 6 The geometry of the welding electrode $(d=15 \mathrm{~mm}$, R7.5)

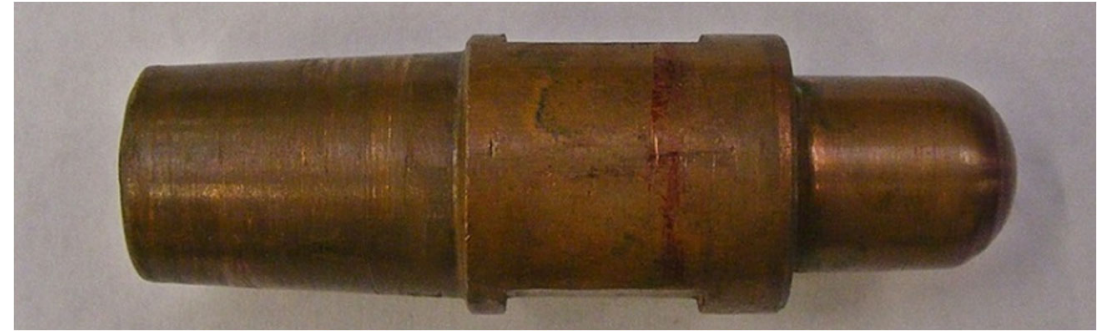

\subsection{Tensile shear tests}

The tensile shear strength of single-lap spot-welded joints is a complex phenomenon, which depends on several factors, namely, welding parameters and base material properties. These factors control the microstructure and size of the weld nugget, which determine the mechanical behaviour of the welds. Test pieces for the tensile shear test were manufactured as shown in Fig. 5. The tests were performed with static loading. In order to gain reliable results 11 test pieces were used in every case according to $\mathrm{EN}$ ISO 14273. The maximal tensile shear forces $\left(F_{\mathrm{ST}}, \mathrm{kN}\right)$ were measured, while the average tensile shear force $\left(F_{\mathrm{ST}}, \mathrm{kN}\right)$, the standard deviation $\left(F_{\mathrm{STSD}}, \mathrm{kN}\right)$ and the standard deviation coefficient $\left(F_{\mathrm{STSDc}}, \%\right)$ were calculated. After the tensile shear tests, we also measured the weld nuggets width $\left(\mathrm{w}_{\mathrm{R}^{*} \mathrm{C}^{*}}, \mathrm{~mm}\right)$ by calliper on each tested sample. We also calculated the average width $\left(w^{\prime}, \mathrm{mm}\right)$, the standard deviation of width $\left(w_{\mathrm{SD}}, \mathrm{mm}\right)$ and the standard deviation coefficient $\left(w_{\mathrm{SDc}}, \%\right)$.

The gained results for the three processing routes and the two surface pre-treatment methods can be seen in Table 5 and on Fig. 9.

First of all, it can be stated that the strength of the welded joints could be further increased by higher welding current, which can be only realized with a higher performance welding equipment. However, from the results, it can be clearly seen that by the application of this pickling receipt, the load bearing capacity of the RSW joints can increase by $20-30 \%$. Furthermore, the less spattering is also an advantage of the oxide removal before joining. The effect of the heat treating condition can be also seen from the experiments, since higher average tensile shear force values were measured when the sheets were artificially aged before or after joining. However, the location of ageing in the production chain did not affect significantly the measured value although post weld ageing is supposed to be more advantageous. The wear of the electrode may influence the tensile shear values through the changing of the weld nugget diameter; therefore, we highlighted the measured weld nugget width. We can state that the average width is between 4.68 and $4.85 \mathrm{~mm}$, and with the $\mathrm{C} 2$ pickle method, the weld nuggets width are always larger, than with the $\mathrm{C} 1$ method. So, the applied surface pre-treatment method is beneficial.

\subsection{Macroscopic test}

For the macroscopic examinations, the cutting of the joints was done by mechanical method, sawing, followed by the grinding of the remaining material layer until the exact centre line of the joint. Then, the surfaces were
Fig. 7 The determined welding cycle diagram for the RSW of AA7075 alloy

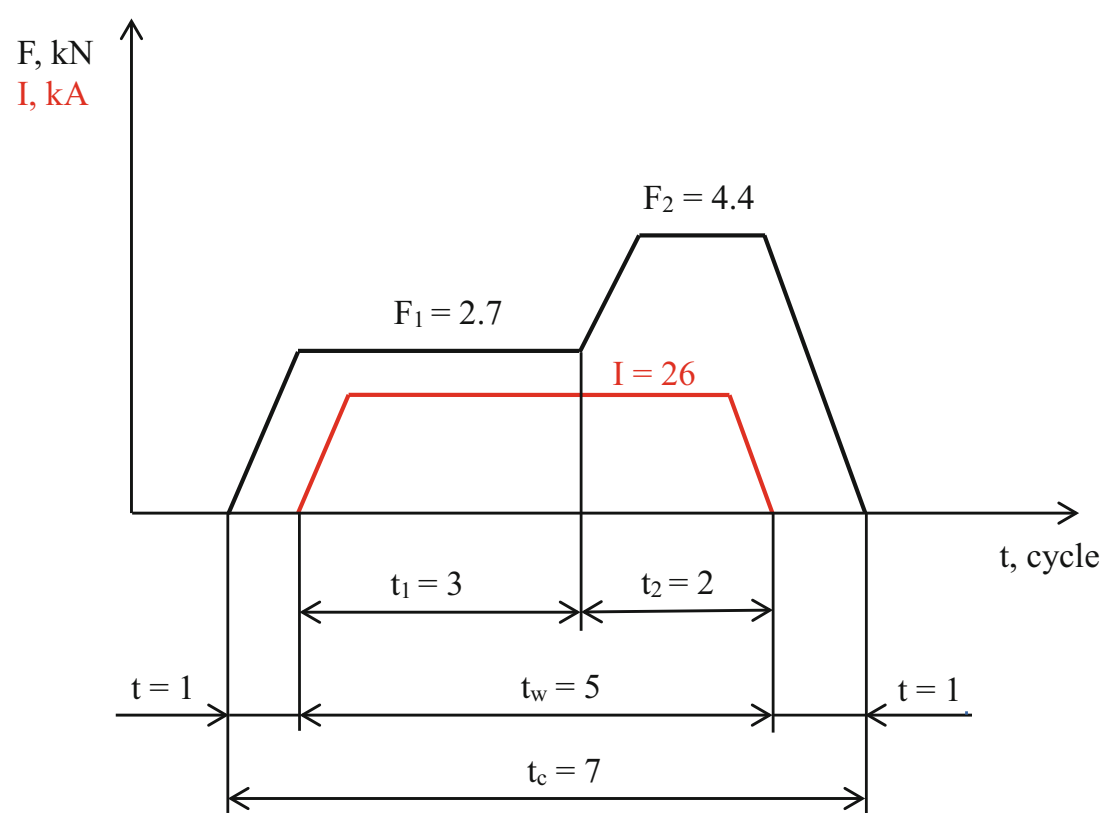


Table 3 The applied surface pre-treatment methods and their receipts

\begin{tabular}{llll}
\hline Receipt & Bath composition & Bath temperature, ${ }^{\circ} \mathrm{C}$ & Immersion time, $\mathrm{s}$ \\
\hline $\mathrm{C} 1$ & Reduced clean: rinse + alcohol & & 10 \\
$\mathrm{C} 2$ & 1st (pre-pickle): $20 \mathrm{~g} \mathrm{NaOH}$ & $80-90$ & $10-30$ \\
& 2nd (pickle): $50 \% \mathrm{HNO}+2 \% \mathrm{HF}$ & 30 & 10 \\
\hline
\end{tabular}

Table 4 The experimental routes (R1-R3) including the heat treating parameters before and after joining

\begin{tabular}{|c|c|c|c|c|}
\hline Route & Process steps & & & Surface pre-treatment method \\
\hline $\mathrm{R} 1$ & SHT $\left(485^{\circ} \mathrm{C} \times 2 \mathrm{~min}\right)$ & - & Joining & $\begin{array}{l}\mathrm{C} 1 \\
\mathrm{C} 2\end{array}$ \\
\hline $\mathrm{R} 2$ & SHT $\left(485^{\circ} \mathrm{C} \times 2 \mathrm{~min}\right)$ & AA $\left(120{ }^{\circ} \mathrm{C} \times 24 \mathrm{~h}\right)$ & Joining & $\begin{array}{l}\mathrm{C} 1 \\
\mathrm{C} 2\end{array}$ \\
\hline $\mathrm{R} 3$ & SHT $\left(485^{\circ} \mathrm{C} \times 2 \mathrm{~min}\right)$ & Joining & $\mathrm{AA}\left(120^{\circ} \mathrm{C} \times 24 \mathrm{~h}\right)$ & $\begin{array}{l}\mathrm{C} 1 \\
\mathrm{C} 2\end{array}$ \\
\hline
\end{tabular}

etched with Kroll's reagent for the $\times 16$ magnification macroscopic images. Besides analysing the joint properties, joint defects and deformations, the images can be also used for the determination of the weld nugget diameter, which was acceptable in all cases. Macroscopic images were made using a digital camera using a Zeiss Stemi 2000 C stereomicroscope (Fig. 10).

The weld nugget shape was regular in every case; only a small asymmetry can be observed, which can be explained by the different conditions of the electrodes. Cracks and other imperfections could not be found in the RSW joints and in the heat-affected zones.

\subsection{Hardness tests}

Vickers microhardness test was applied, where the loading force was $2 \mathrm{~N}$ and the step of the measuring sequence

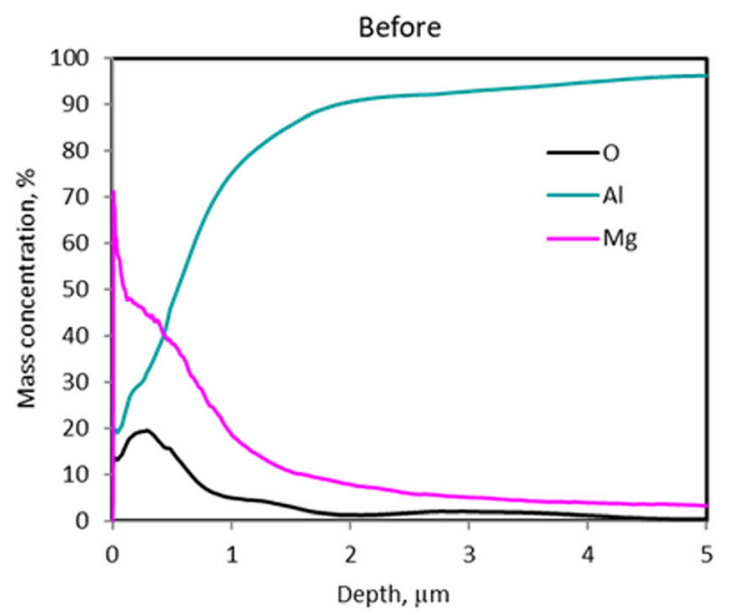

elements was $0.2 \mathrm{~mm}$. The measuring sequence started in one of the base materials and was gone through the weld nugget diagonally, then was ended again in the base material. The measured hardness values can be seen in Fig. 11. Since the surface pre-treatment methods $(\mathrm{C} 1$ and $\mathrm{C} 2)$ do not affect the hardness test results, therefore we only show one hardness distribution per rout (R1, R2, R3).

The diagram clearly shows that in the weld nugget and in the HAZ, a significant softening can occur due to the welding heat input. In the weld nugget, the softening can be originated from the melting of the material and after the fast solidification, where is no time for the precipitation hardening processes. In the HAZ depending on the distance from the fusion line, a solid solution zone and a partially annealed overaged zone are formed which hardness is generally lower than the base material in $\mathrm{T} 6$ condition.

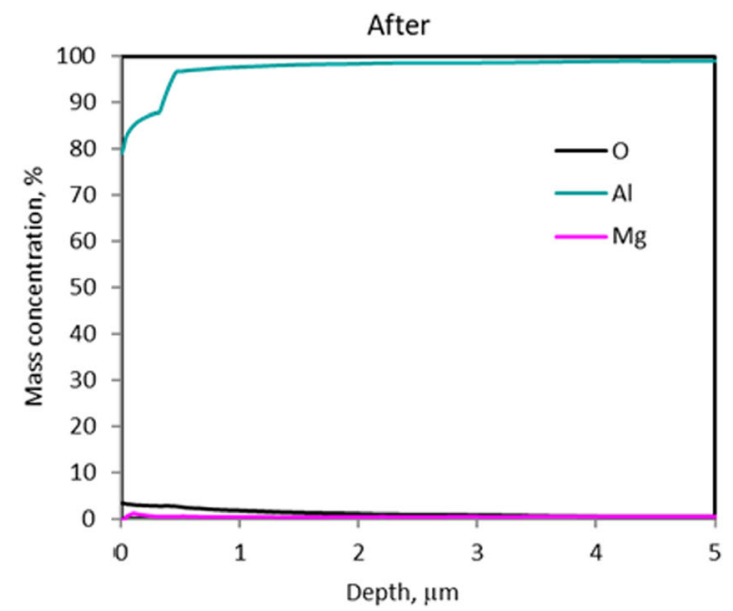

Fig. 8 Surface composition of AA7075 before and after pre-treatment. Material has been SHT treated 
Table 5 Results of the tensile shear tests and nuggets width measurements

\begin{tabular}{|c|c|c|c|c|c|c|c|c|c|c|c|c|}
\hline \multirow[t]{2}{*}{ Specimen } & \multicolumn{4}{|l|}{$\mathrm{R} 1$} & \multicolumn{4}{|l|}{ R2 } & \multicolumn{4}{|l|}{$\mathrm{R} 3$} \\
\hline & $\mathrm{C} 1$ & $w_{R I C l}(\mathrm{~mm})$ & $\mathrm{C} 2$ & $w_{R I C 2}(\mathrm{~mm})$ & $\mathrm{C} 1$ & $w_{R 2 C l}(\mathrm{~mm})$ & $\mathrm{C} 2$ & $w_{R 2 C 2}(\mathrm{~mm})$ & $\mathrm{C} 1$ & $w_{R 3 C l}(\mathrm{~mm})$ & $\mathrm{C} 2$ & $w_{R I C 2}(\mathrm{~mm})$ \\
\hline 1 & 2.05 & 4.70 & 2.60 & 4.85 & 2.35 & 4.75 & 2.85 & 4.80 & 2.25 & 4.65 & 2.85 & 4.85 \\
\hline 2 & 2.05 & 4.70 & 2.45 & 4.80 & 2.30 & 4.75 & 3.33 & 4.85 & 2.50 & 4.80 & 3.33 & 4.85 \\
\hline 3 & 2.20 & 4.65 & 2.65 & 4.85 & 2.25 & 4.70 & 3.05 & 4.85 & 3.75 & 4.80 & 3.05 & 4.80 \\
\hline 4 & 2.15 & 4.65 & 2.95 & 4.85 & 2.60 & 4.80 & 3.75 & 4.90 & 2.50 & 4.80 & 3.75 & 4.80 \\
\hline 5 & 2.05 & 4.65 & 2.55 & 4.80 & 2.25 & 4.70 & 3.25 & 4.80 & 2.35 & 4.80 & 3.25 & 4.80 \\
\hline 6 & 2.20 & 4.70 & 2.35 & 4.75 & 2.35 & 4.75 & 3.05 & 4.85 & 2.75 & 4.80 & 3.05 & 4.90 \\
\hline 7 & 2.20 & 4.70 & 2.40 & 4.80 & 2.30 & 4.75 & 2.85 & 4.85 & 2.25 & 4.65 & 2.85 & 4.85 \\
\hline 8 & 2.05 & 4.65 & 2.60 & 4.85 & 2.35 & 4.75 & 3.38 & 4.85 & 2.65 & 4.80 & 3.38 & 4.85 \\
\hline 9 & 2.05 & 4.65 & 2.40 & 4.80 & 2.25 & 4.70 & 4.05 & 5.00 & 2.36 & 4.80 & 4.05 & 4.80 \\
\hline 10 & 2.45 & 4.80 & 2.35 & 4.75 & 2.55 & 4.85 & 3.15 & 4.75 & 3.35 & 4.85 & 3.15 & 5.05 \\
\hline 11 & 2.05 & 4.70 & 3.00 & 4.75 & 2.55 & 4.85 & 3.25 & 4.95 & 2.85 & 4.80 & 3.25 & 4.85 \\
\hline$F_{\mathrm{ST}}{ }^{\prime}, \mathrm{kN}$ & 2.14 & - & 2.57 & - & 2.37 & - & 3.27 & - & 2.69 & - & 3.29 & - \\
\hline$F_{\mathrm{STSD}}, \mathrm{kN}$ & 0.12 & - & 0.23 & - & 0.13 & - & 0.36 & - & 0.48 & - & 0.36 & - \\
\hline$F_{\mathrm{STSDc}}, \%$ & 5.84 & - & 8.75 & - & 5.52 & - & 11.11 & - & 17.74 & - & 11.11 & - \\
\hline$w^{\prime}, \mathrm{mm}$ & - & 4.68 & - & 4.80 & - & 4.76 & - & 4.86 & - & 4.78 & - & 4.85 \\
\hline$w_{\mathrm{SD}}, \mathrm{mm}$ & - & 0.05 & - & 0.04 & - & 0.05 & - & 0.07 & - & 0.06 & - & 0.07 \\
\hline$w_{\mathrm{SDc}}, \%$ & - & 0.01 & - & 0.01 & - & 0.01 & - & 0.01 & - & 0.01 & - & 0.01 \\
\hline
\end{tabular}

From the three investigated processing routes, the R1 resulted in the lowest hardness distribution since the base material was in SHT condition and there was no ageing after joining. In this case, the hardening of the HAZ compared with the soft base material can be explained by the ageing effect of welding heat input which cannot be considered as over ageing in present case. R2 shows the classical hardness distribution when a heat treatable aluminium alloy is welded. It is important to note that the hardness of the weld nugget drops down to the half of the precipitation hardened base material. In case of
$\mathrm{R} 3$, the hardness of the HAZ increased up to the demanded level of the base material due to post weld ageing which can be explained by the complex characteristics of the heataffected zone (HAZ) structure.

It is important to highlight that independently from the heat treating condition, the weld nugget softened to the same level. Less softening of the weld nugget may be achieved by the change of the microstructure and the (re)solution of the precipitated alloying elements. The application of pulsed RSW may further improve the properties of the weld nugget. It
Fig. 9 The effect of two-step chemical surface etching and heat treatment condition on the average tensile shear force, with the standard deviation values

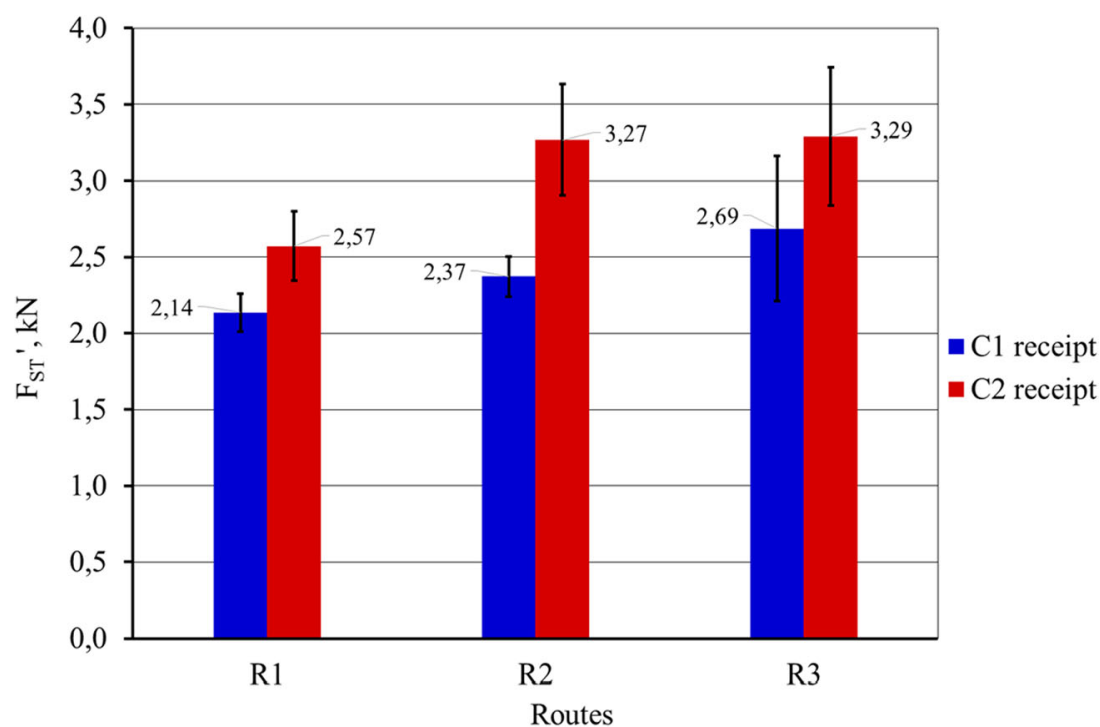


Fig. 10 Cross section of a welded joint of $t=1 \mathrm{~mm}$ AA 7075 alloy (magnification $\times 16$ )

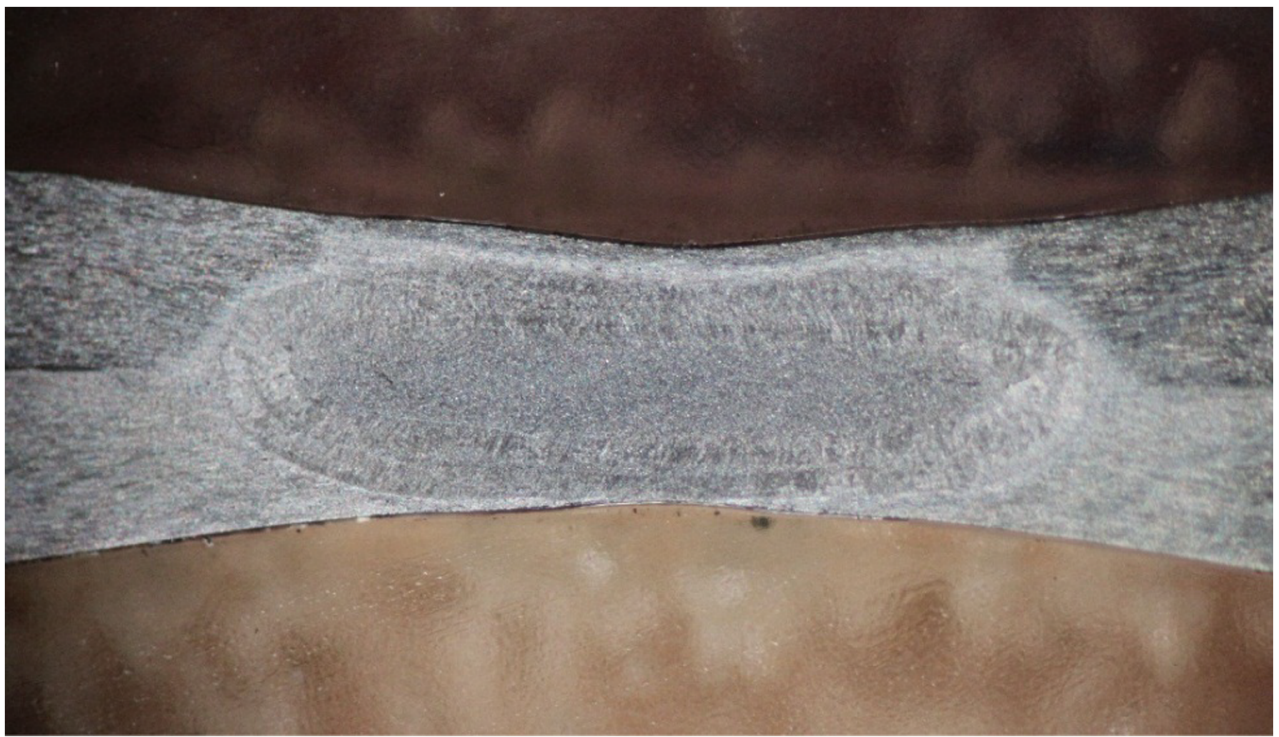

should be important to mention that the conventional heat treating circumstances of the 7075 alloy were applied during these experiments; however, within our research aims, there is a motion to shorten the time of the solution annealing and the artificial ageing according to the industrial expectations.

\section{Conclusions}

In the present paper, the resistance spot weldability (RSW) of the $7 \mathrm{xxx}$ group was investigated. AA7075 type aluminium alloy $(t=1 \mathrm{~mm})$ in $\mathrm{F}$ temper condition was selected for the experimental program. The weldability of this alloy was examined in general and then in terms of the effect of a general surface pre-treatment processes and heat treating condition. The welding parameters were set based on the previously determined welding lobe. The RSW joints were produced according to a hard work program and therefore the upper welding current limit ( $26 \mathrm{kA}$ ) of our welding equipment used for the experiments including a post pressing force in order to realize the achievable highest strength joints. It is important to note that by extra hard work program, the joint properties could be further developed. According to the results, the following conclusions can be drawn:

1. Based on the performed tensile shear tests, the designed pickling method (C2) could improve by $20-30 \%$ the mechanical properties of the AA7075 RSW joints. By the
Fig. 11 Hardness distribution at the weld cross section in different processing routes

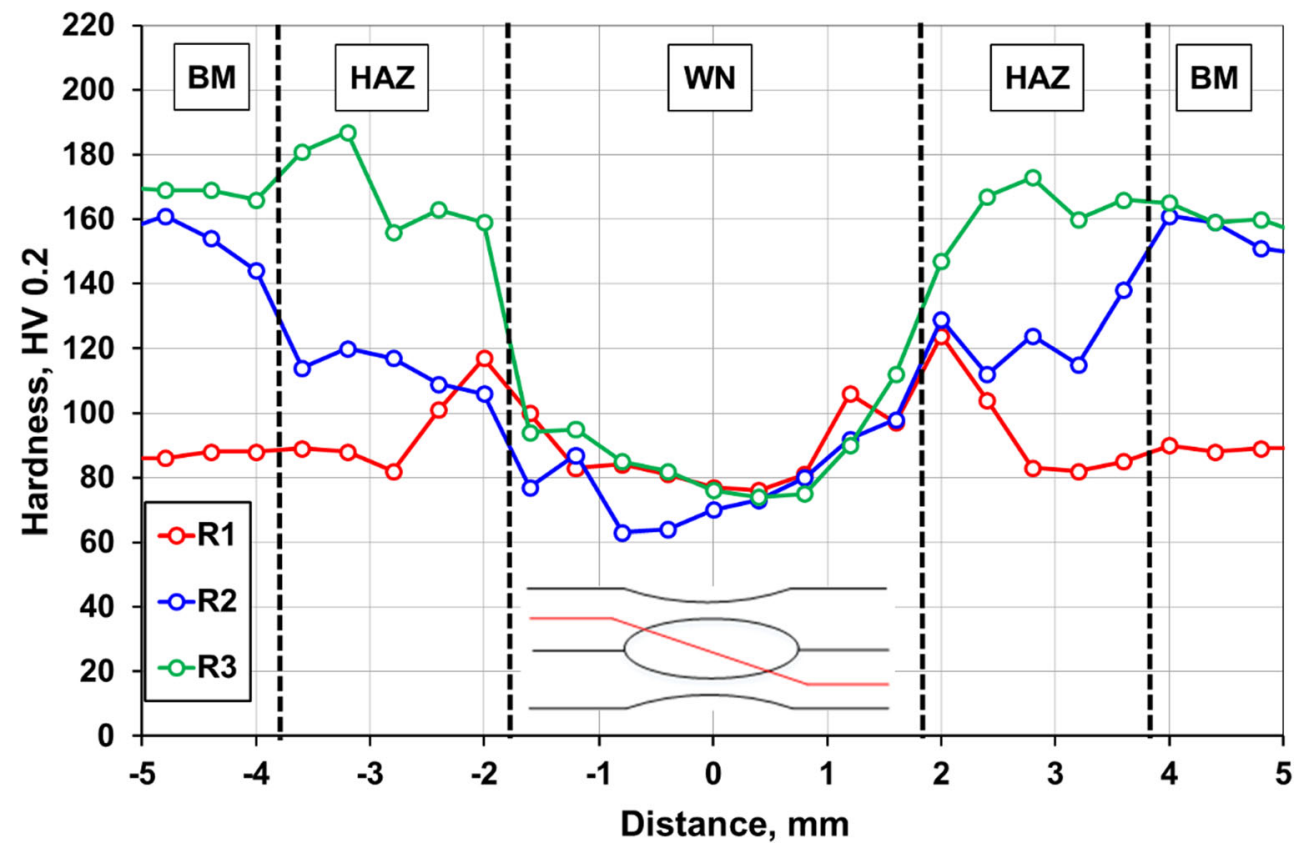


application of the surface pre-treatment methods, the spattering and the electrode wear can be decreased, so this method can increase also the electrode lifetime. The average weld nugget width is between 4.68 and $4.85 \mathrm{~mm}$, and with the $\mathrm{C} 2$ pickle method, the weld nuggets widths are always larger, than with the $\mathrm{C} 1$ method. So, the applied surface pre-treatment method is beneficial.

2. The chemical oxide removal can be integrated into the production line before the welding, so a slight increase of the production time and costs can be expected, while the quality and the reliability can significantly develop. However, the examinations should be extended by cost analysis due to the expected longer production time and the industrial implementation should be further studied.

3. The heat treating condition had a significant effect on the hardness and thus the strength of RSW joints. The lowest strength joints were produced when the aluminium sheets were welded in solution heat treated (SHT) condition and post weld ageing was not applied. If the ageing was performed before or after joining, the strength of the RSW joints significantly improved. However, the best results were achieved when the precipitation hardening followed the welding. By artificial ageing after joining, the hardness distribution of HAZ significantly increases and reaches the level of the base material in T6 condition; however, the weld nugget remains soften which can be connected to the segregation of the main alloying elements.

4. The implementation of hot forming and in-die quenching (HFQ) process into the production chain of car-body elements, including ageing after forming and joining, opens the possibility to improve the properties and compensate the softening of RSW joints. For future work, the experimental program is planned to be extended by the investigation of the more realistic circumstances of HFQ process, including the developed fast ageing technology and its effects on joint properties.

Acknowledgements Open access funding provided by University of Miskolc. HFQ is a registered trademark of Impression Technologies Limited, who has exclusive commercialization rights to HFQ technology.

Funding The authors thank the European Commission for their support on the H2020 project "Low Cost Materials Processing Technologies for Mass Production of Lightweight Vehicles (LoCoMaTech)", Grant No.: H2020-NMBP-GV-2016 (723517).

Open Access This article is licensed under a Creative Commons Attribution 4.0 International License, which permits use, sharing, adaptation, distribution and reproduction in any medium or format, as long as you give appropriate credit to the original author(s) and the source, provide a link to the Creative Commons licence, and indicate if changes were made. The images or other third party material in this article are included in the article's Creative Commons licence, unless indicated otherwise in a credit line to the material. If material is not included in the article's Creative Commons licence and your intended use is not permitted by statutory regulation or exceeds the permitted use, you will need to obtain permission directly from the copyright holder. To view a copy of this licence, visit http://creativecommons.org/licenses/by/4.0/.

\section{References}

1. Sakurai T (2008) The latest trends in aluminium alloys sheets for automotive body panels. Kobelco Technol Rev 28:22-28

2. Taban E, Gould JE, Lippold JC (2010) Characterization of 6061-T6 aluminum alloy to AISI 1018 steel interfaces during joining and thermo-mechanical conditioning. Mater Sci Eng A 527:1704-1708

3. Florea RS, Solanki KN, Bammann DJ, Baird JC, Jordon JB, Castanier MP (2012) Resistance spot welding of 6061-T6 aluminum: failure loads and deformation. Mater Des 34:624-630

4. Lukács J, Meilinger Á, Pósalaky D (2017) Fatigue curves for aluminium alloys and their welded joints used in automotive industry. Mater Sci Forum 885:86-91

5. Tisza M, Zs L, Kovács PZ, Budai D (2017) Some recent developments in sheet metal forming for production of lightweight automotive parts. J Phys Conf Ser 896(1):012087. https://doi.org/10. 1088/1742-6596/896/1/012087

6. Eggers J, Bothfel R, Jansen T (2017) Challenges and solutions in resistance welding of aluminium alloys - dealing with non predictable conditions. Lect Notes Mech Eng 1:469-481

7. Fakir OE, Wang L, Balint D, Dear JP, Lin J, Dean TA (2014) Numerical study of the solution heat treatment, forming, and indie quenching (HFQ) process on AA5754. Int J Mach Tool Manu 87:39-48

8. Garret RP, Lin J, Dean TA (2005) An investigation of the effects of solution heat treatment on mechanical properties for AA 6xxx alloys: experimentation and modelling. Int J Plast 21(8):1640-1657

9. Hayat F (2012) Effect of aging treatment on the microstructure and mechanical properties of the similar and dissimilar 6061-T6/7075T651 RSW joints. Mater Sci Eng A 556:834-843

10. Temmar M, Hadii M, Sahraoui T (2011) Effect of post-weld aging treatment on mechanical properties of tungsten inert gas welded low thickness 7075 aluminium alloy joints. Mater Des 32:3532-3536

11. Grohmann T (2016) Forming of AMAG 7xxx series aluminium sheet alloys, International Conferences on New Developments in Sheet Metal Forming and New Developments in Hydroforming. Fellbach, Germany: 85-102

12. Balogh A, Lukács J, Török I (2015) Weldability and the properties of the welded joints (in Hungarian). University of Miskolc, Research on automotive steel and aluminium alloys, pp 60-75

13. Leroy D, Siewer T A, Liu S, Edwards GR (1994) ASM handbook vol. 6: welding brazing and soldering, ASM International, p 1356

14. Hayat F (2011) The effects of the welding current on heat input, nugget geometry, and the mechanical and fractural properties of resistance spot welding on $\mathrm{Mg} / \mathrm{Al}$ dissimilar materials. Mater Des 32:2476-2484

15. Cotell C M, Sprague J A, Smidt F A (1994) ASM handbook vol. 5: surface engineering, ASM International, pp 13-184

16. Han L, Thronton M, Boomer D, Shergold M (2010) Effect of aluminium sheet surface conditions on feasibility and quality of resistance spot welding. J Mater Process Technol 210:1076-1082

17. Patil RR, Tilak A, Srivastava V, De A (2011) Minimising electrode wear in resistance spot welding of aluminium alloys. Sci Technol Weld Join 16(6):509-513

Publisher's note Springer Nature remains neutral with regard to jurisdictional claims in published maps and institutional affiliations. 